\title{
Espacialización y análisis del proceso de ocupación de unidades territoriales residenciales en la circunscripción IV, Río Gallegos
}

\author{
Spatialization and analysis of the occupation process of territorial residential units in \\ circumscription IV, Río Gallegos \\ Merlina L. Saldivia, Cristhian S. González, Cristian Ampuero, Alicia P. Cáceres \\ merlinasaldivia.22@gmail.com, cristhiang_93@hotmail.com.campuero@uarg.unpa.edu.ar, \\ acaceres@uarg.unpa.edu.ar \\ Universidad Nacional de la Patagonia Austral (UNPA) \\ Unidad Académica Río Gallegos (UARG) \\ Instituto de Ciencias del Ambiente, Sustentabilidad y Recursos Naturales (ICASUR) Campus \\ Universitario UARG - Av. Gregores y Piloto "Lero" Rivera S/N Santa Cruz, Río Gallegos
}

Recibido: 28/05/2020. Aceptado: 14/12/2020

\begin{abstract}
RESUMEN
El presente trabajo tuvo por objetivo reconocer y espacializar las Unidades Territoriales Residenciales (UTR) de la Circunscripción IV, Secciones B y C de la Tercera Franja Residencial (TFR) respectivamente, de la ciudad de Río Gallegos, Provincia de Santa Cruz, Argentina. La metodología que sustentó la investigación comprendió salidas de campo, recopilación y lectura de bibliografía científica, relevamiento de ordenanzas, cartografía, fotografías aéreas e imágenes satelitales. La información recolectada se procesó a través de un Sistema de Información Geográfica (SIG), y se identificaron UTR, nueve en la Sección B y seis en la Sección C. Los resultados aportan a la zonificación del uso del suelo que debe realizar el Municipio de la ciudad de Río Gallegos.
\end{abstract}

Palabras clave: Geografía Urbana; Paisaje Urbano; Rururbano Intraejidal; Estructura Urbana Interna; Tercera Franja Residencial.

\begin{abstract}
The present paper aimed to recognize and spatialize the Residential Territorial Units of Circumscription IV - Section B and C of the Third Residential Band of the city of Río Gallegos, province of Santa Cruz, Argentina. The methodology that supported the research included field trips, collection and reading of scientific bibliography, ordinance survey, cartography, aerial photographs and satellite images. The collected information was processed through a Geographic Information System (GIS), and RTUs were identified, nine in Section B and six in Section C. The results will contribute to the zoning of land use by the Municipality of the city of Río Gallegos.
\end{abstract}

Keywords: Urban Geography; Urban Landscape; Rururban Intraejidal; Internal Urban Structure; Third Residential Strip. 


\section{INTRODUCCIÓN}

La Estructura Urbana Interna de la ciudad de Río Gallegos comprende dos grandes áreas con divisiones propias: Urbana y Rururbana (Cáceres y García, 2004). En cuanto a la primera, se ubica dentro del ejido municipal y comprende al Área Central, Segunda Franja Residencial y Tercera Franja Residencial; mientras que la segunda, comprende parte dentro y fuera del ejido, denominándose Intraejidal y Extraejidal respectivamente.

La Tercera Franja Residencial (TFR) comienza a consolidarse a fines del siglo XX, a través de la demanda de tierras para uso residencial, producto del crecimiento demográfico que experimentó la ciudad. El avance, ocupación y uso del suelo en la TFR en tanto emergente de su contexto, generó contradicciones en las políticas de planificación urbana al exceder los límites impuestos desde la normativa del Estado Municipal para uso residencial del suelo.

En cuanto al Área Rururbana Intraejidal (ARI), está caracterizada por la presencia de chacras subdivididas en lotes de dimensiones urbanas.

El Estado municipal tiene dos formas de dividir y denominar los sectores del ejido que no son coincidentes y no se encuentran articulados entre sí. Por un lado, "la designación catastral" que abarca todo el ejido municipal y comprende los aspectos fiscales y de registro dominial de la parcela, estableciendo unidades que, de mayor a menor, son: Circunscripción (7 denominadas en números romanos) y las Secciones (denominadas en letras mayúsculas, variando la cantidad según la Circunscripción, las manzanas y las parcelas).

Por este motivo, este trabajo tiene como objetivo reconocer y espacializar UTR de la Circunscripción IV - Sección B y C, como aporte, desde el diagnóstico territorial, a la zonificación de usos del suelo que debe realizar la Municipalidad.

Como hipótesis se plantea que el uso del suelo residencial en la Circunscripción IV Secciones B y C permite reconocer e identificar Unidades Territoriales Residenciales, teniendo en cuenta la uniformidad, homogeneidad y cohesión territorial del área, en función de sus características geográficas, históricas, arquitectónicas y sociales.

Los resultados aportan en el diagnóstico territorial de la ciudad, para identificar, entre otros, las áreas ocupadas con usos residenciales, para la posterior zonificación respecto a los terrenos disponibles, para la proyección urbanística del municipio.

\section{MARCOS DE REFERENCIA}

\section{MARCO TEÓRICO - CONCEPTUAL}

El trabajo se enmarca teóricamente en la Geografía Urbana, la cual es una rama de la Geografía y que según Pertile (2007) es aquella que estudia fenómenos tales como el crecimiento urbano y demográfico en relación a la ciudad, como así también, aspectos referidos al dinamismo de los espacios internos que se dan por dentro de ésta, a saber, calles, barrios, áreas comerciales, etc. En tanto rama intra-disciplinar, busca explicar las relaciones que se dan por dentro de la ciudad y también los vínculos que se generan con otros núcleos urbanos.

La ciudad, abordada desde la geografía es entendida por Sorre (1952:180) como “...una aglomeración de hombres más o menos considerable, densa y permanente, con un elevado grado de organización social: generalmente independiente para su alimentación del territorio sobre el cual se desarrolla, e implicando por su sistema una vida de relaciones activas, necesarias para el sostenimiento de su industria, de su comercio y de sus funciones". En coincidencia con esto, Villalvazo Peña, Corona Medina y García Mora (2002) sostienen que las ciudades son "... centros neurálgicos en los cuales se concentra el poder económico, 
político, social, cultural y demográfico. Son nodos que conforman redes, entendidas como espacios de flujo con jerarquías definidas, cuyas ventajas comparativas y competitivas son superiores al resto de las estructuras espaciales" (Villalvazo Peña, Corona Medina y García Mora, 2002:18).

La ciudad puede ser analizada en función de su morfología, entendida, según Aguilera (1999) como el estudio de la apariencia y la forma del ambiente físico urbano, donde la forma de la ciudad es el resultado de influencias funcionales, económicas, técnicas y sociales, que tienen lugar dentro de un tiempo y espacio específico. Para Vilagrasa (1991) la morfología urbana es el estudio de la forma urbana y de los procesos y personas que la modelan. Ello significa, que sin el estudio de las contingencias socioculturales y económicas que envuelven a la ciudad, difícilmente podrá darse una visión dinámica y comprensiva de las transformaciones de sus paisajes. Pero, por otra parte, estos fenómenos son entendidos como variables independientes, y se analizan, principalmente como productores de formas. Para él, los procesos sociales y la actitud de los agentes sirven, tan solo, para sistematizar, y entender mejor, aquello que vemos cotidianamente y que constituye el paisaje urbano.

En este sentido, el paisaje urbano es considerado por Sgroi (2016) como el resultado de la conjunción de tres componentes, a saber, el plano, el uso del suelo y la edificación, los cuales son condicionantes para arribar a la comprensión de la morfología de las ciudades y el estudio de lo urbano per se.

El área de estudio se corresponde con un tipo de plano ortogonal, el cual según Sánchez Hernández (2016) se caracteriza por un trazado de forma perpendicular que deviene en una imagen similar a la de un tablero de ajedrez. Este tipo de plano clasifica en tipología como regular y por lo general denota una planificación previa que está regulada, sin embargo, en la circunscripción IV se observan excepciones a la regla, aún tratándose de un trazado que se asemeja al ortogonal.

En cuanto al plano de la Circunscripción IV - Sección B, se observa que en dirección al Norte la forma del trazado es en forma de cuadrados y rectángulos que hacen a un tipo de plano ortogonal. En dirección al Sur, se observa que, si bien no hay una simetría en cuanto a las figuras geométricas y la relación entre ellas, respetan la forma de cuadrado y rectángulo.

Por otro lado, en la Sección C, al Norte también se observa la forma del trazado en forma de cuadrados y rectángulos hacen a un tipo de plano ortogonal. En dirección al Sur, se observa la forma del trazado en forma de triángulo.

Con respecto a los usos del suelo, Santos (2000) conceptualiza el uso real del suelo en tanto manifestación concreta en el territorio de una o más actividades, como así también, formas de ocupación, de lo cual se desprenden prácticas de los actores sociales que construyen un vínculo dentro de lo urbano. En consecuencia con ello, podemos encontrar los siguientes usos del suelo que predominan en el espacio urbano: residencial, administrativo, comercial, industrial, entre otros.

Este trabajo tiene como eje central o foco el uso del suelo residencial, entendido como aquel espacio en el que la población reside. Sin embargo, en las situaciones en las que sea necesario se hará mención a los posibles usos del suelo, ya sea administrativo, comercial, industrial, etc. En el área de estudio, si bien los usos permitidos son el residencial, industrial mixto y rural, por los bajos valores inmobiliarios de la subdivisión de chacras se han comprado más de dos lotes lindantes para usos como el comercial mayorista, depósitos, talleres, lavaderos de transporte pesado, empresas de transportes pesados, con respecto a los usos deportivos en ambientes cubiertos y al aire libre se encuentran en proceso incipiente, pero cabe aclarar que no son construidos por el Estado. Como resultado, se observa una desorganizada ocupación por la presencia de diferentes usos del suelo y en algunos casos, por la incompatibilidad de usos del suelo. A los efectos de una eficiente gestión del territorio, es necesaria la redacción de una ordenanza de usos del suelo y zonificación. 
Sobre la tipología arquitectónica, se destaca la patagónica. Según Mirelman, Lolich y Fernandez Mallo (2006), esta tipología “...se caracteriza por la construcción en madera y chapa que sigue los modelos ingleses traídos por los colonos pioneros desde Malvinas. [...] Sus elementos característicos son: muros y techos de chapa corrugada, cubiertas con fuerte pendiente, ventanas de vidrio repartido, algunas a guillotina, bow-windows, galerías vidriadas...”. (Mirelman, Lolich y Fernandez Mallo, 2006:147).

Al conjugarse estos tres componentes se obtienen como resultado el paisaje urbano. En palabras de Zarate Martin (1991) el mismo representa “... la imagen visual, el lenguaje espacial que expresa estilos de vida, modelos y condiciones de organización socioeconómica que se han sucedido a través del tiempo" (Zárate Martín, 1991:73).

El paisaje urbano puede ir transformándose a lo largo de los años, siendo el uso del suelo el que más varía, y también, la edificación, pero en menor medida, por todo el tiempo que implica el proceso de construcción. El tipo de plano es el que más perdura en el tiempo, en virtud de la inversión que se realiza para la delimitación de las circunscripciones, manzanas y parcelas, formando parte de la morfología urbana de un territorio.

Río Gallegos, como toda ciudad patagónica, conforma modelos diferentes a los de otras regiones del país porque han experimentado transformaciones recientes y constantes, además en el territorio de la provincia de Santa Cruz la extensa superficie y las condiciones físicoclimáticas extremas modifican este tipo particular de crecimiento. En el crecimiento urbano aparecen nuevas formas urbanas en el siglo XXI, las cuales son producto de la combinación de distintos factores que responden a realidades locales y no globales; a excepción del aeropuerto internacional, no aparecen las nuevas formas de crecimiento asociadas a los "artefactos de la globalización" que plantea De Mattos (2001) como producto de la globalización; "shoppings centers, barrios cerrados, edificios inteligentes, centros empresariales, complejos para el esparcimiento, [...] hoteles cinco estrellas, nuevos aeropuertos internacionales, conjuntos empresariales, megaproyectos inmobiliarios, equipamientos de consumo...”). El estudio de crecimiento urbano de Río Gallegos, de acuerdo a lo propuesto por Cáceres (2013) se realiza a partir de la definición de cortes temporales que responden a cambios en los ritmos de crecimiento de la población migrante, atraídos por las posibilidades de trabajo generadas por diversas causales históricas, económicas, políticas, demográficas. Luego, en cada etapa de crecimiento se reconocen elementos de fijación y barreras, en ambos casos naturales y antrópicos, que permitieron e impidieron, respectivamente, el avance urbano como así también la superación de las barreras".

Respecto a la Estructura Urbana Interna de Río Gallegos, Cáceres y García (2004) plantean que comprende dos grandes áreas con divisiones propias: Urbana y Rururbana. En cuanto a la primera, se ubica dentro del ejido municipal y comprende al Área Central, Segunda Franja Residencial y Tercera Franja Residencial; mientras que la segunda, comprende parte dentro y fuera del ejido, denominándose Intraejidal y Extraejidal respectivamente. Cabe aclarar que el límite occidental ha variado debido a ampliaciones del ejido municipal entre 2013 y 2018 realizado por la Honorable Cámara de Diputados.

La consolidación de la Tercera Franja Residencial (TFR) comienza en el Siglo XX en virtud del proceso de crecimiento demográfico que tuvo como efecto la demanda de tierras para su uso habitacional. Siguiendo a Cáceres (2013) citada en Ampuero, Cáceres, Norambuena, Frias, Segovia, Melgarejo (2018) son dos hechos los que permitieron la superación de las barreras antrópicas del Borde Urbano y el crecimiento urbano de la ciudad: "En primer lugar, se destaca la recuperación de terrenos de las Fuerzas Armadas hacia el sureste de la ciudad; y, en segundo lugar, la sustitución del Ramal Ferro industrial Río Turbio por la Av. Balbín y el cierre del muelle Río Turbio del puerto de Río Gallegos, al oeste de la ciudad." (Ampuero, Cáceres, Norambuena, Frias, Segovia, Melgarejo, 2018:2). 
El avance, ocupación y uso del suelo en la TFR en tanto emergente de su contexto, generó contradicciones en las políticas de planificación urbana al exceder los límites impuestos desde la normativa del Estado Municipal para uso residencial del suelo. En este sentido, sostienen Cáceres, Norambuena, Ampuero y Triviño (2013) que "el avance urbano tiene como consecuencia la consolidación del área en la TFR, de modo espontáneo, sin planificación [...], el Estado municipal no reconoce a la franja en su conjunto, hay ausencia de políticas de planificación urbana de modo integrado entre el Estado nacional, provincial y municipal. De este modo, se profundiza el carácter monocéntrico de Río Gallegos, la periferia no ofrece equipamiento, infraestructura y servicios." (Cáceres, Norambuena, Ampuero y Triviño, 2013:58).

En términos de Carut (2012), el periurbano se caracteriza por "la yuxtaposición de usos, conviviendo y enfrentándose parcelas rurales de pequeñas dimensiones (menores de 5 ha) con espacios urbanos, grandes equipamientos y otros usos [...] es un espacio genérico que rodea a cualquier ciudad independientemente de su actividad, función o tipo de ocupación" (Carut, 2012:3).

Acerca del rurubano, la misma autora manifiesta"... aunque tiene las mismas características que lo periurbano, es la zona rural la que ejerce la predominancia, sin que estas pierdan totalmente sus atributos territoriales (económicos, sociales) como sucede en el periurbano. Es decir que si bien se observa una cierta alternancia armónica entre la estructura rural y la urbana, donde alternan usos residenciales, industriales y de servicios, las actividades agrarias aún mantienen una cierta importancia." (Carut, 2012:3)

En cuanto al Área Rururbana Intraejidal (ARI) está caracterizada por la presencia de chacras subdivididas en lotes de dimensiones urbanas. Acerca de su conformación histórica, Cáceres, Sáenz, Melgarejo y Ampuero (2011) mencionan que:

En los ochenta, ante la falta de tierras fiscales dentro del área urbana y el alto porcentaje de chacras improductivas, una fuerte especulación inmobiliaria favoreció loteos de dimensiones urbanas vendidos a particulares, cuya ocupación se lleva a cabo con viviendas de uso permanente principalmente y vivienda de carácter secundario. De este modo, la expansión de estos usos fuera del área urbana no le dio al municipio tiempo de ordenar este espacio en forma eficiente por lo tanto genera un crecimiento urbano descontrolado. (Cáceres, Sáenz, Melgarejo y Ampuero, 2011:7)

En la misma línea, debe comprenderse que las necesidades de los sujetos son multidimensionales y no se agotan al satisfacer únicamente la demanda habitacional, puesto que el proceso de ocupación del suelo para uso residencial también supone la garantía de otros derechos como parte de las competencias del Estado para la reproducción cotidiana de los ciudadanos: el acceso a una vivienda digna, como así también, el acceso a la salud, a la educación, a la recreación, etc., derechos inalienables y transversales a todos los ciudadanos en pos de generar un ambiente que permita desarrollar las potencialidades desde un enfoque comunitario que constituya la identidad colectiva.

Refiriendo a características que hacen a la vida cotidiana de los ciudadanos que habitan la Tercera Franja Residencial (TFR) y a los Nodos de Servicio, González y Cáceres (2018), citando a Cáceres y Ampuero (2008) sostienen que:

El crecimiento y ensanchamiento urbano de la ciudad en la TFR generó distancias importantes hacia el centro, situación que se ve agravada por las inclemencias climáticas (bajas temperaturas en invierno y vientos fuertes en verano) y por un servicio de transportes de colectivos deficiente y costoso. El abastecimiento de servicios y equipamientos dependen algunos de la administración provincial, otros de la municipal y se localizan en parcelas cercanas que comprenden unas pocas manzanas, cuya concentración constituyen "Nodos de Servicios" (Cáceres y Ampuero, 2008) que favorecen la descentralización y que atraen otros usos como el comercial." (González y Cáceres, 2018:6). 
El Estado municipal tiene dos formas de dividir y denominar los sectores del ejido que no son coincidentes ni articuladas entre sí. Por un lado, "la designación catastral" que abarca todo el ejido municipal y comprende los aspectos fiscales y de registro dominial de la parcela y establece unidades que, yendo de mayor a menor, son: la Circunscripción ( 7 denominadas en números romanos), las secciones (denominadas en letras mayúsculas y varían la cantidad según la Circunscripción), las manzanas y las parcelas.

A modo de síntesis, se define que una Unidad Territorial Residencial es un espacio que demuestra homogeneidad y cohesión territorial particularmente por constituirse como un área en donde predomina el uso del suelo residencial y que presenta características geográficas, históricas, arquitectónicas y sociales que le otorgan uniformidad (Saldivia y Cáceres, 2018:21; González y Cáceres, 2018:7).

\section{MARCO HISTÓRICO-GEOGRÁFICO}

La ciudad de Río Gallegos es la capital de la provincia de Santa Cruz. Pertenece al departamento Güer Aike que el Censo 2010 del INDEC contabilizó 113.267 habitantes y según el mismo Censo, Río Gallegos contó con 95.796 habitantes (INDEC, 2010).

El sitio de Río Gallegos es $51^{\circ} 38^{\prime}$ Latitud Sur, y $69^{\circ} 17^{\prime}$ ' Longitud Oeste, siendo la ciudad más austral de la Patagonia Continental Argentina (Fig. 1).
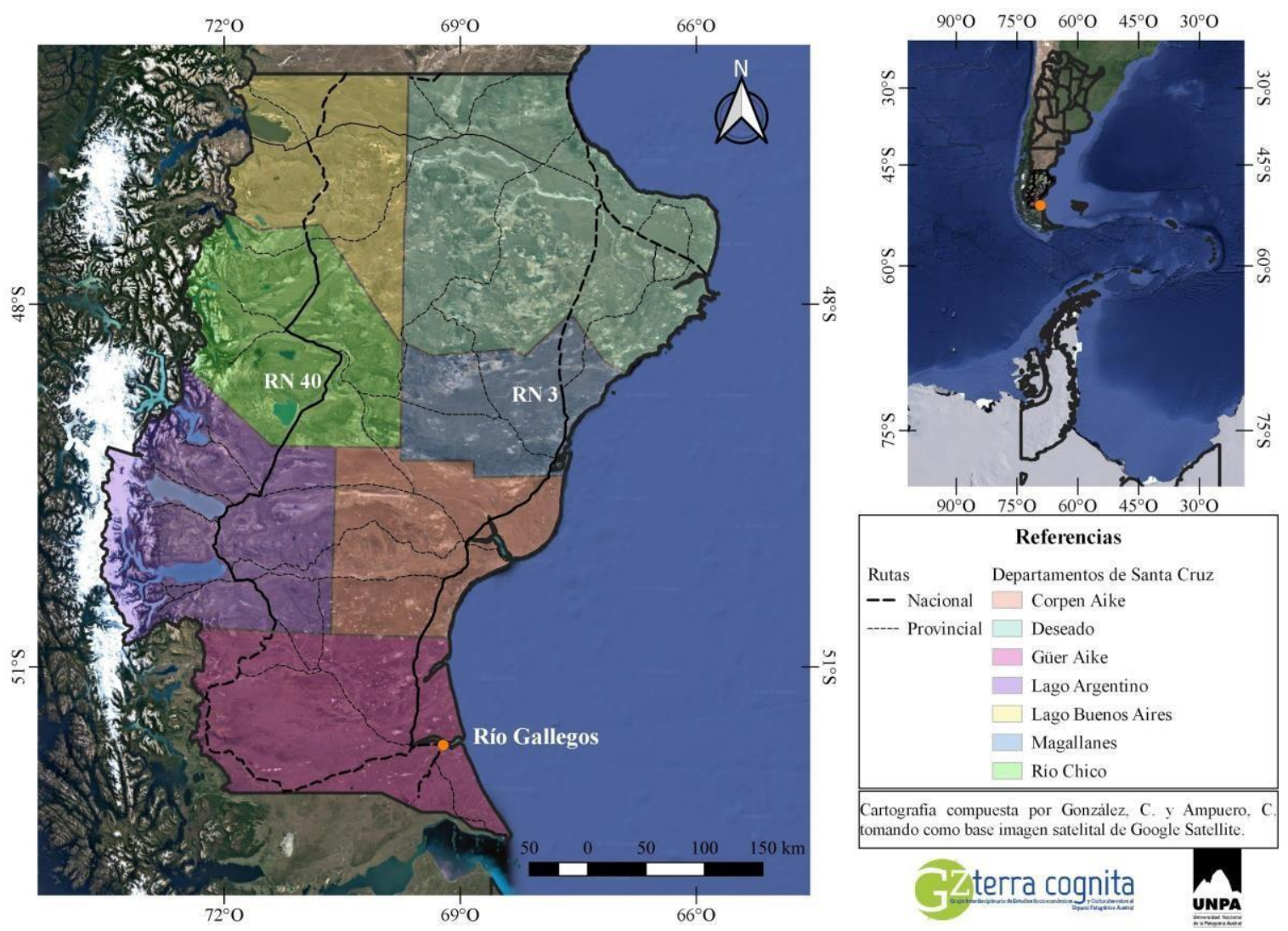

Fig. 1. Posición Geográfica de la ciudad de Río Gallegos.

Fuente: Elaborado por González, C. y Ampuero, C. tomando como base imagen satelital de Google Satellite.

Respecto al emplazamiento de Río Gallegos, Cáceres, Norambuena, Ampuero y Triviño (2013) sostienen que:

... está emplazada sobre la margen sur del estuario del río Gallegos, sobre terrazas fluviales y algunos paleocauces, a una altura media por debajo de los 20 m.s.n.m. Se encuentra ubicada 
desde el punto de vista fisiográfico en el denominado Patagonia Austral Extraandina (dentro del ecosistema Estepa Magallánica), con ausencia absoluta de árboles, propio del tipo de clima de esta zona, frío semiárido de meseta con precipitaciones que no superan los $300 \mathrm{~mm}$ anuales. La latitud es un condicionante de la vida urbana puesto que corresponde a la zona de libre circulación atmosférica y oceánica; que explica la presencia de vientos fuertes del Oeste, la falta de verano térmico y los días largos del verano y las noches largas del invierno. Por lo tanto, el emplazamiento se caracteriza por la aridez, vientos fuertes y mesetas de suave relieve que generan un paisaje natural, monótono y hostil. (Cáceres, Norambuena, Ampuero y Triviño, 2013:2)

La Situación de Río Gallegos, según Cáceres, Segovia Stanoss, Soto, Norabuena, Frias y Ampuero (2016) puede ser estudiada en la historia a partir de tres cortes temporales que dan cuenta del contexto particular de la ciudad:

- 1920 a 1960: situación de encrucijada de ejes de comunicaciones de cabotaje asociados a la producción ganadera y minera;

- 1960 a 2000: situación de encrucijada de ejes de comunicaciones a la producción minera, la administración pública y el turismo;

- 2000 a la actualidad: situación de encrucijada de ejes de comunicaciones asociados a la producción minera y la administración pública.

\section{RESULTADOS, ANÁLISIS Y DISCUSIÓN}

\section{METODOLOGÍA}

La metodología que le dio encuadre y sustentó al presente trabajo es cuantitativa, puesto que el reconocimiento y espacialización de Unidades Territoriales Residenciales (UTR) implicó su cuantificación, y, asimismo, la correlación de diversas variables (usos del suelo, proceso de ocupación del suelo, entramado y tipología de vivienda) que éstas comprenden.

En cuanto a las ramas del enfoque cuantitativo, el trabajo fue descriptivo en virtud de que, en un primer momento, en los resultados se dio cuenta de las características de las UTR, y explicativo puesto que a partir de la correlación de las variables en la síntesis y en la discusión se pudo explicar la conformación de las UTR en el área de estudio.

Se realizó en un primer momento un relevamiento y lectura de bibliografía específica para la construcción del marco teórico conceptual, para lo cual se tomaron aportes de la Geografía Urbana, la cual comprende el estudio del Paisaje Urbano y la Estructura Urbana Interna. En el marco de ello se conceptualizó Unidad Territorial Residencial, aporte significativo que genera este trabajo.

Posteriormente, se realizó el relevamiento de información técnica sobre la Circunscripción IV - Sección B y C, compuesto por documentos tales como ordenanzas municipales y cartografía antigua provista por el Archivo Histórico Municipal, fotografías aéreas históricas e imágenes satelitales actuales a los fines de profundizar el conocimiento del área de estudio, y se delimitaron UTR de manera provisoria.

Se realizaron dos salidas de campo. En la primera de ellas se logró el primer acercamiento al área de estudio, para ejercitar el reconocimiento, desde el campo disciplinar de la Geografía, de la Estructura Urbana Interna y el Paisaje Urbano de Río Gallegos: el área urbana y rururbana intra y extra-ejidal; el Área Central, la Segunda y Tercera Franja Residencial; la división en circunscripciones, manzanas, y lotes; el tipo de plano, usos del suelo y edificación. El objetivo de esta salida radicó en un conocimiento general que permitió el reconocimiento 
del área de estudio enmarcado en un fenómeno aún más grande: la ciudad. También permitió junto con la lectura de bibliografía específica, el diseño de una planilla de relevamiento para la segunda salida de campo.

La segunda salida de campo, consistió en un recorrido por la totalidad de la Circunscripción IV - Sección B y C, y en tanto insumo técnico-instrumental, se utilizó la planilla de relevamiento diseñada previamente en gabinete para la carga de información proveniente de la observación directa, datos de coordenadas geográficas con GPS, y tomas de fotografías.

Finalmente, se realizó el trabajo de gabinete, donde se digitalizaron las UTR en un Sistema de Información Geográfica (SIG), a las cuales se les asignó una letra del alfabeto siguiendo el sentido de las agujas del reloj. El software utilizado para llevar a cabo la cartografía fue QGIS en su versión 3.8. "Zanzíbar".

\section{RESULTADOS}

Los puntos extremos del Sitio del área de estudio (Sección B y C de la Circunscripción IV. Fig. 2) son:

- Norte: $51^{\circ} 37^{\prime} 9.46^{\prime \prime}$ LS y $69^{\circ} 15^{\prime} 77^{\prime}$ ' LO

- Este: $51^{\circ} 38^{\prime} 347.54^{\prime \prime}$ LS y $69^{\circ} 14^{\prime}$ ' 9.32' 'LO

- Sur: $51^{\circ} 40^{\prime} 42.17^{\prime \prime}$ LS y $69^{\circ} 16^{\prime} 31.73^{\prime \prime}$ 'LO

- Oeste: $51^{\circ} 39^{\prime} 39.5^{\prime \prime}$ 'LS y $69^{\circ} 16^{\prime} 26.19^{\prime \prime}$ LO

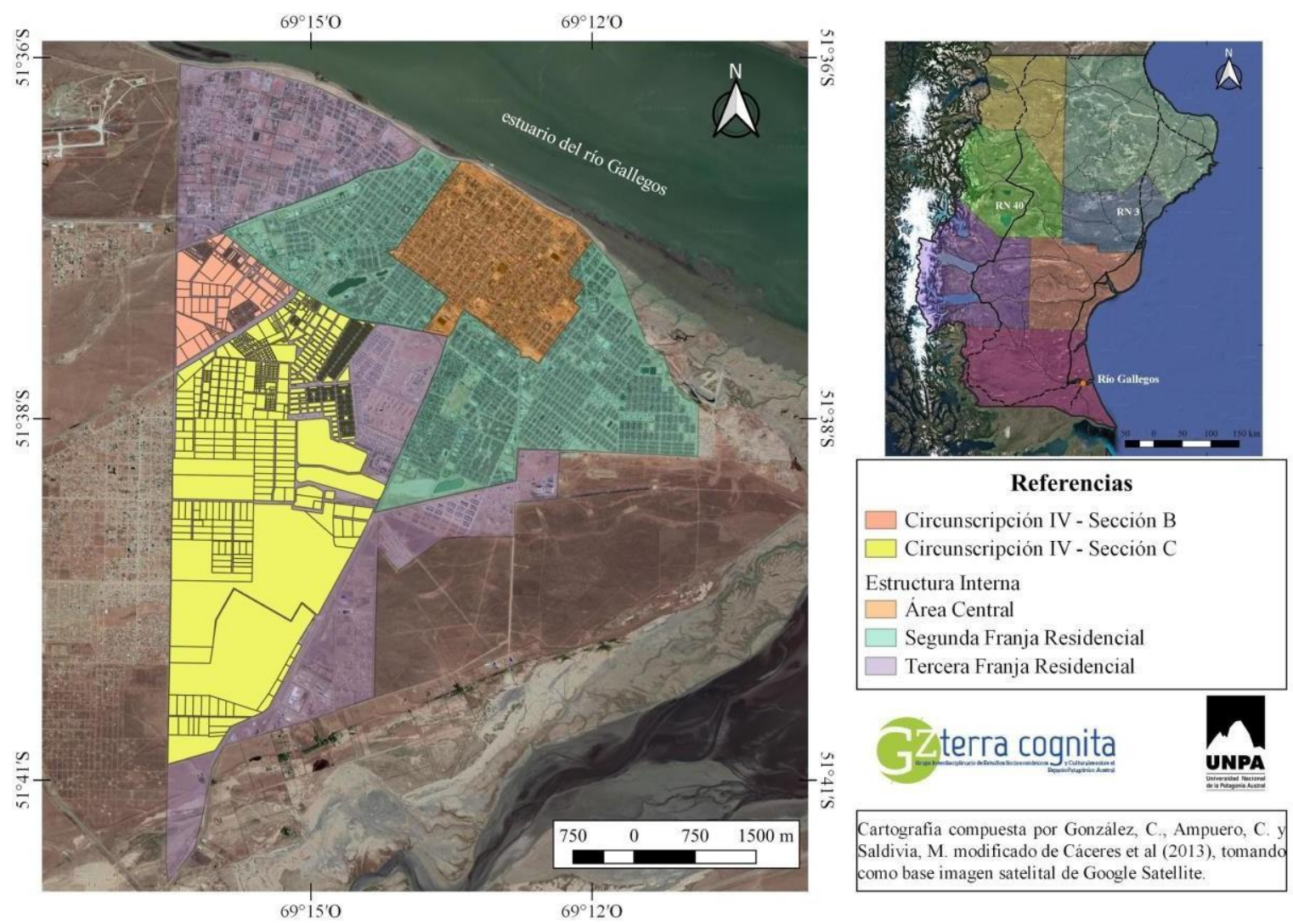

Fig. 2. Ubicación de la Circunscripción IV - Sección B y C en relación a la Estructura Urbana Interna de Río Gallegos. Fuente: Elaborado por González, Ampuero y Saldivia, modificado de Cáceres et al (2013), tomando como base imagen satelital de Google Satellite.

En cuanto al Emplazamiento, el área de estudio es atravesado desde Este a Oeste por dos paleocauces. En la Sección B uno de $11 \mathrm{~m}$ de profundidad, siendo la continuidad de la laguna 
María la Gorda. Mientras que la Sección C lo atraviesa un paleocauce de $10 \mathrm{~m}$ de profundidad siendo la continuidad de la laguna Ortiz.

La Situación es extrema con respecto a la ciudad, se comunica con el resto de Río Gallegos a través de la Avenida Asturias y la Autovía 17 de Octubre en el caso de la Sección B. La Sección C se comunica con las antes mencionadas y la Av. San Martín.

En cuanto a la Estructura Urbana Interna, el área de estudio comprende una superficie aproximada de $11.82 \mathrm{~km}^{2}$. Pertenece a la TFR, teniendo como límites:

- Norte: intersección entre ex terraplén ramal ferroviario Río Turbio y Paseo de los Arrieros

- Este: Av. San Martín

- Sur: Intersección entre Av. San Martín y Calle 1

- Oeste: Calle 1/ Luis Federico Leloir

Al sur de cada Sección, corresponde al Área Rururbana Intraejidal (ARI), donde chacras improductivas han sido loteadas y vendidas para el uso residencial, con servicios básicos de energía, gas en red, pero con ausencia de un Nodo de Servicios.

A partir del trabajo de campo, se reconocieron y espacializaron un total de nueve UTR en la Sección B (Fig. 3) y seis en la Sección C de la Circunscripción IV (Fig. 4).

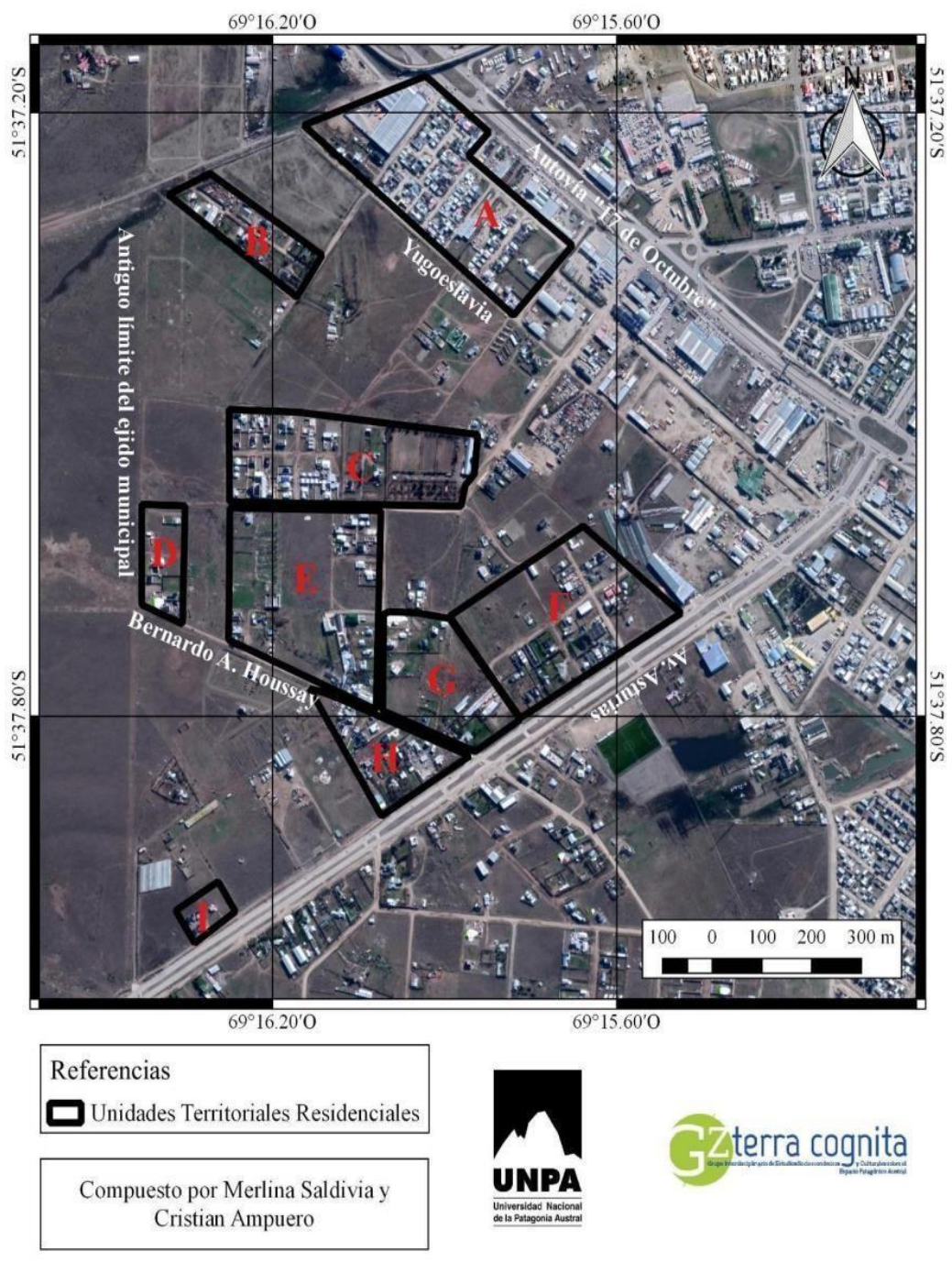

Fig. 3. Unidades Territoriales Residenciales (UTR) en la Circunscripción IV, Sección B.

Fuente: Elaborado por Saldivia, M. y Ampuero, C., tomando como base imagen satelital de Google Satellite 


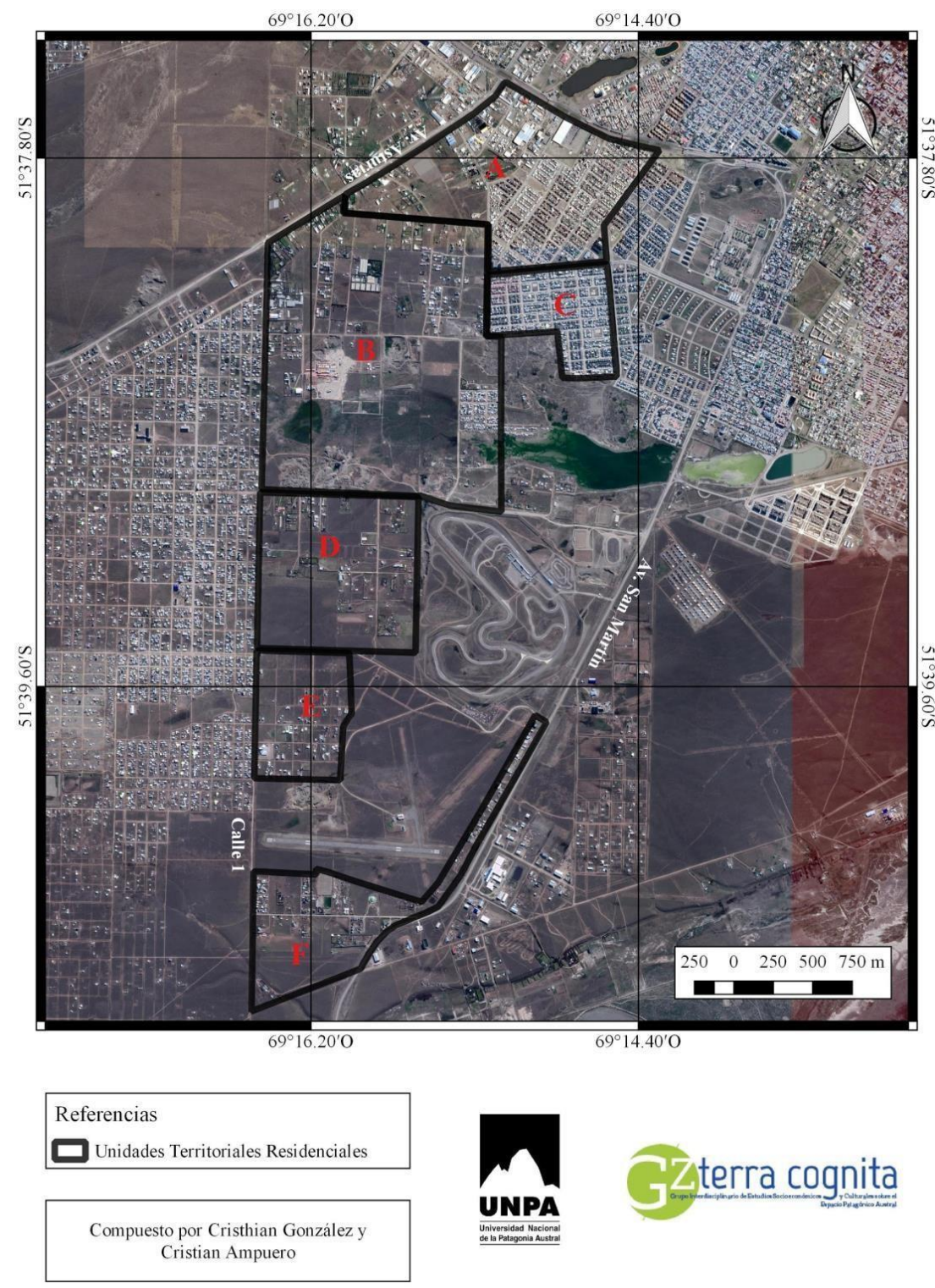

Fig. 4: Unidades Territoriales Residenciales, Circunscripción IV, Sección C.

Fuente: Elaborado por González, C. y Ampuero, C. tomando como base imagen satelital de Google Satellite.

\section{DISCUSIÓN}

A partir de la correlación existente entre las variables presentadas en las tablas de análisis, es decir, el uso del suelo, el proceso de ocupación, el entramado, y el tipo de vivienda / tipología arquitectónica, se analizan las Unidades Territoriales Residenciales (UTR) identificadas:

\section{Sección B:}

UTR A: el proceso de ocupación del suelo es consolidado, predomina el uso del suelo residencial con viviendas unifamiliares de entramado cerrado y tipología patagónica, aunque en algunos lotes se observa la presencia de diversos tipos de viviendas. Cabe aclarar que la presencia de otros usos del suelo es mínima, entre los que se menciona el uso comercial.

UTR B: el proceso de ocupación está en proceso de consolidación, predomina el uso residencial con una mayoría de viviendas unifamiliares con entramado abierto, y tipología 
patagónica. Cabe destacar que en esta UTR se encuentra una vivienda de entramado cerrado. UTR C: el proceso de ocupación es incipiente, predomina el uso residencial con mayoría de viviendas unifamiliares con entramado abierto.

UTR D: el proceso de ocupación es incipiente, predomina el uso residencial con viviendas multifamiliares de entramado abierto, y tipología patagónica. Cabe destacar que hay una escasa presencia de viviendas unifamiliares.

UTR E: el proceso de ocupación es incipiente, predomina el uso residencial con viviendas multifamiliares de entramado abierto. Cabe destacar que hay una escasa presencia de viviendas unifamiliares y otros usos del suelo: comercial e industrial.

UTR F: el proceso de ocupación es consolidado, predomina el uso residencial con viviendas unifamiliares de entramado abierto, y tipología patagónica.

UTR G: el proceso de ocupación es incipiente, predomina el uso residencial, con viviendas unifamiliares de entramado abierto, y tipología patagónica.

UTR H: el proceso de ocupación es incipiente, predomina el uso residencial con viviendas multifamiliares de entramado abierto, y tipología patagónica.

UTR I: el proceso de ocupación es incipiente, predomina el uso residencial con viviendas unifamiliares con entramado abierto, y tipología patagónica.

De la correlación de las variables identificadas en las UTR, se presenta el siguiente mapa síntesis (Fig. 5).

A modo de síntesis, se plantea que la confluencia de la Avenida Asturias y Autovía 17 de Octubre actúan como eje de fijación para el proceso de ocupación del suelo en términos de uso residencial: en tanto en la UTR A el proceso es continuo, en las UTR pertenecientes al Área RurbanaIntraejidal (ARI) es discontinuo. Por tal motivo, se afirma que en la Circunscripción IV - Sección B, el proceso de ocupación es consolidado al NE y, en la medida que se transita hacia el SO, el proceso de ocupación es incipiente.

Del análisis del área de estudio se desprende que hay una tendencia al tipo de vivienda unifamiliar y de tipología patagónica. Asimismo, se destaca la predominancia en gran parte de la Sección del entramado abierto, lo cual se relaciona al proceso de ocupación incipiente y discontinuo. No obstante, la excepción a tal afirmación es la UTR A, puesto que la totalidad de los lotes se encuentran ocupados, con la presencia de entramado cerrado.

\section{Sección C:}

UTR A: El uso de suelo predominante es el Residencial. El proceso de ocupación es consolidado. Presenta un entramado de tipo cerrado y las viviendas poseen una tipología patagónica. Con respecto al tipo de vivienda es de tipo unifamiliar.

UTR B: El uso del suelo predomina el uso residencial con un proceso de ocupación consolidado. Presenta un entramado cerrado, con una tipología de tipo patagónica. El tipo de vivienda que prevalece es el unifamiliar.

UTR C: Con respecto al uso del suelo impera el tipo residencial, con una ocupación que se encuentra en proceso de consolidación acelerado. El entramado es abierto y la tipología de vivienda es la patagónica. El tipo de vivienda es unifamiliar.

UTR D: El uso del suelo es de tipo residencial, con un proceso de ocupación incipiente. Posee en su mayoría un entramado abierto, con una tipología de vivienda de tipo patagónica y predominio de viviendas unifamiliares.

UTR E: El tipo de uso de suelo predominante es el residencial, con un proceso de ocupación incipiente. Presenta un entramado abierto con una tipología de vivienda patagónica y de tipo unifamiliar. 


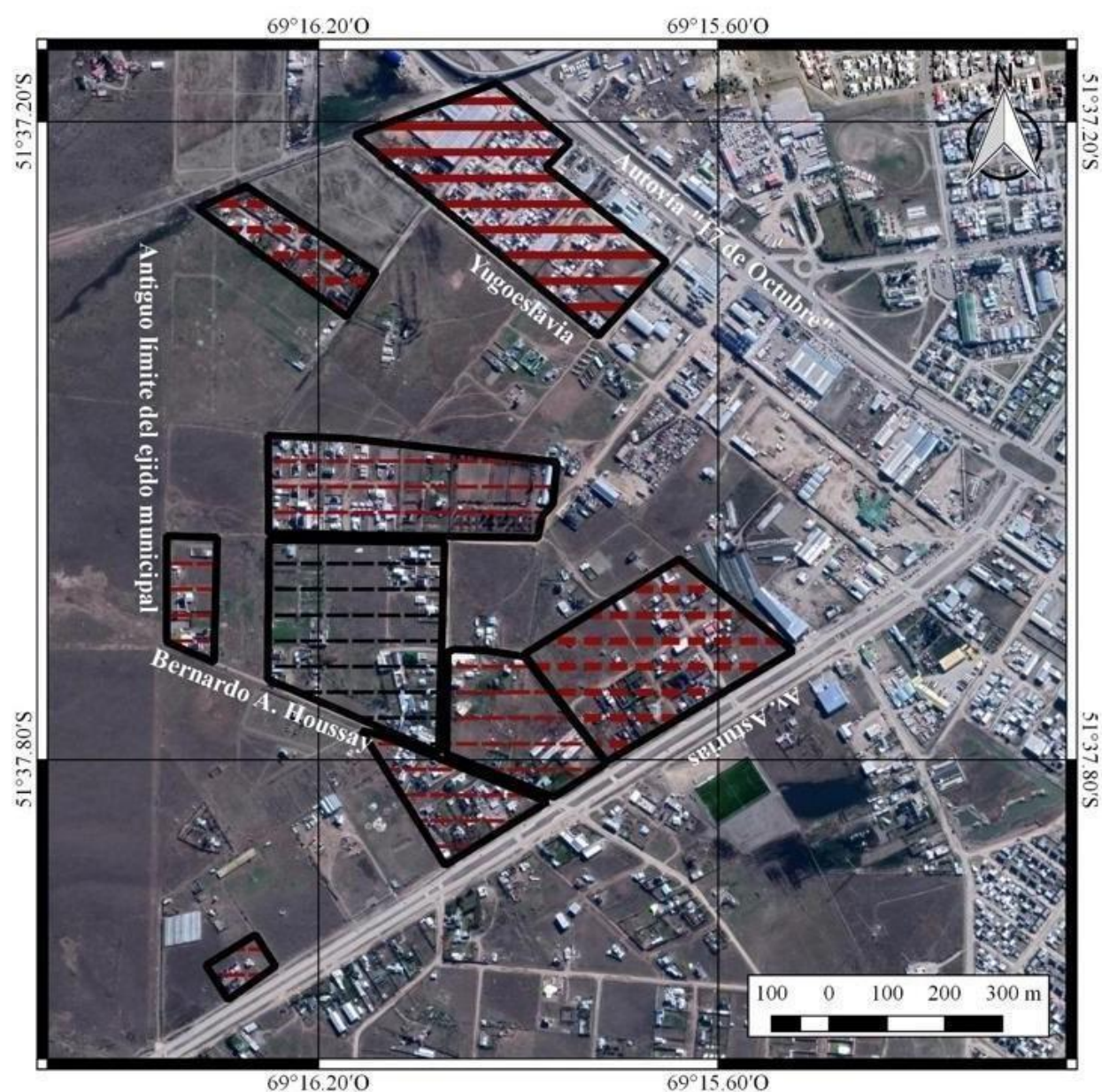

Leyenda

Proceso de ocupación, entramado y tipología arquitectónica en las UTR

- Proceso de ocupación consolidado, entramado cerrado con tipología patagónica

- Proceso de ocupación consolidado, entramado abierto con tipología patagónica

-- Proceso de ocupación incipiente, entramado abierto con tipologia patagónica

-- Proceso de ocupación incipiente, entramado abierto con tipologia no patagónica

UNPA 2 terra cognita $\begin{gathered}\text { Compuesto por Cristhian González y } \\ \text { Cristian Ampuero }\end{gathered}$

Fig. 5. Proceso de ocupación, entramado y tipología arquitectónica en las UTR.

Fuente: Elaborado por González, C. y Ampuero, C., tomando como base imagen satelital de Google Satellite.

UTR F: El uso de suelo predominante es el residencial con un proceso de ocupación incipiente. Posee en su mayoría un entramado de tipo abierto, con una tipología patagónica y viviendas unifamiliares.

A partir de la correlación de las variables identificadas en las UTR, se presenta el mapa síntesis (Fig. 6).

Luego del análisis realizado, se determinó que la confluencia de la Avenida Asturias con la Autovía "17 de Octubre" actúa como ejes de fijación para el proceso de ocupación consolidado y continuo para el uso residencial, acompañado de un entramado cerrado y con elementos de la tipología patagónica, como el techo a dos aguas.

A medida que se direcciona hacia el sur por la Av. Asturias y siguiendo por la Calle 1, esta 
consolidación va desapareciendo y es sustituida por el entramado de tipo abierto, manteniendo la tipología patagónica, a lo largo de toda la Circunscripción.

Se observa una tendencia a la no homogeneidad, ya que se encuentra solo en el sector más cercano a la Av. Asturias y Autovía "17 de Octubre".

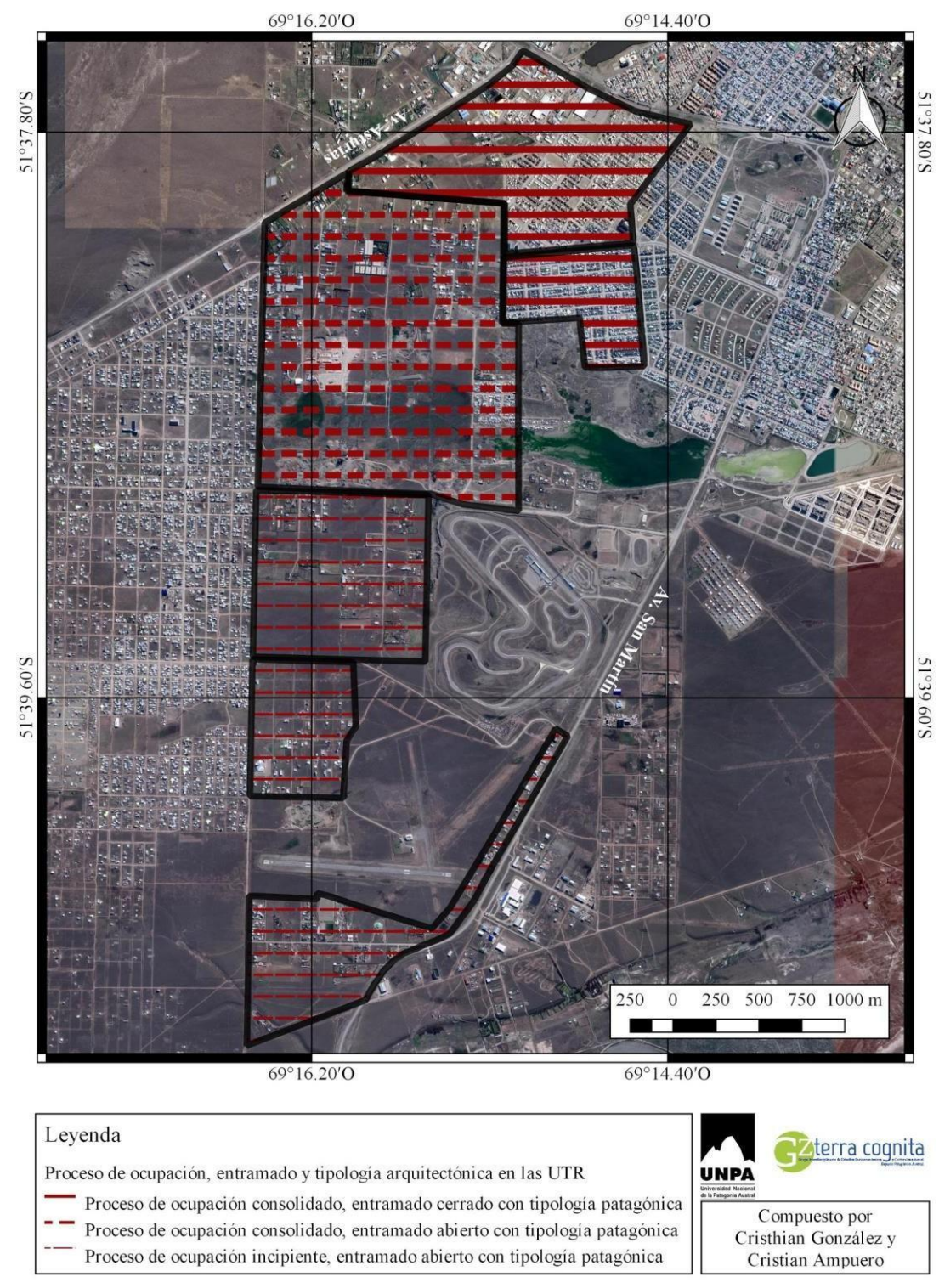

Fig. 6. Proceso de ocupación, entramado y tipología arquitectónica en las UTR.

Fuente: Elaborado por González, C. y Ampuero, C., tomando como base la imagen satelital de Google Satellite

\section{CONCLUSIONES}

En virtud de lo expuesto, el objetivo de esta investigación, reconocer y espacializar Unidades Territoriales Residenciales (UTR), efectivamente se logró al haberse delimitado y caracterizado un total de nueve UTR en la Sección B y seis UTR en la Sección C, abordadas desde el estudio de la Geografía Urbana, teniendo en cuenta dos ejes: el Paisaje Urbano (tipo de plano, usos del suelo y edificación) y la Estructura Urbana Interna (TFR - ARI).

La hipótesis planteada inicialmente se confirma, puesto que del análisis realizado se pudieron 
reconocer e identificar Unidades Territoriales Residenciales homogéneas en relación al uso del suelo residencial, por medio de sus características geográficas, históricas, arquitectónicas y sociales.

La metodología adoptada ha sido la correcta ya que ha permitido que los objetivos se cumplan de manera efectiva, integrando la información relevada en un SIG.

Los resultados obtenidos en esta investigación, realizan un aporte en el diagnóstico territorial de la ciudad de Río Gallegos, para identificar, entre otros, las áreas ocupadas con usos residenciales, con la finalidad de llevar a cabo una zonificación respecto a los terrenos disponibles, para la proyección urbanística del municipio.

Asimismo, este trabajo de investigación realiza un significativo aporte para la formación de los estudiantes como futuros profesionales de Trabajo Social y Geografía, poniendo en práctica la redacción científica y la utilización de diferentes herramientas para generar cartografía.

Por último, se destaca que los resultados aportan parcialmente al Proyecto de Investigación 29A/PDTS380 “Tercera Franja Residencial de Río Gallegos: Diagnóstico territorial de áreas con ausencia y presencia de cobertura de servicios. Propuesta de localización de Nodos de Servicios", sobre marco teórico, conceptual y metodología.

\section{AGRADECIMIENTOS}

A la Universidad Nacional de la Patagonia Austral y Consejo Interuniversitario Nacional por financiar las "Becas Estímulo a las Vocaciones Científicas para estudiantes de grado" y "Becas de Iniciación a la Investigación para Estudiantes de Grado y Pregrado de la Universidad Nacional de la Patagonia Austral", en el marco de la cual se desarrollaron los trabajos.

Al Proyecto de Investigación 29A/PDTS380, por el financiamiento de las salidas de campo. Al Archivo Histórico Municipal de Río Gallegos por permitir la revisión de los expedientes consultados.

\section{REFERENCIAS}

AGUILERA, A. (1999). “Ciudades fractales y telarañas urbanas”. Vetas, Revista de El Colegio de San Luis. p. 50.

AMPUERO, C., CÁCERES, A. P., NORAMBUENA, M., FRIAS, P., SEGOVIA, M., MELGAREJO, G. (2018). "Diagnóstico Territorial de la Tercera Franja Residencial de Río Gallegos, Patagonia Austral Argentina. Aportes de Becarios Estudiantes de la UNPA. Río Gallegos”. Revista Contribuciones Científicas. Vol. 30. GÆA, Sociedad Argentina de Estudios Geográficos. Buenos Aires.

CÁCERES A. P., GARCÍA, A. N. (2004). "Diferenciación interna del espacio Geográfico de Río Gallegos: Estudio Preliminar”. IGEOPAT. Párrafos geográficos. Año II No 3.

CÁCERES, A. P., SÁENZ, J. L., MELGAREJO, G., AMPUERO, C. (2011). "Definición de estratos residenciales en el Área Rururbana Intraejidal de Río Gallegos; Ciudad intermedia de la Patagonia Austral Argentina". II Congreso Nacional de Departamentos de Geografía de Universidades Públicas. Santa Fe.

CÁCERES, A. P. (2013). "Crecimiento urbano de la ciudad de Río Gallegos. Capital de la provincia de Santa Cruz, Patagonia Austral Argentina (1985 - 2010)”. Revista Científica de Geografía $\mathrm{N}^{\circ} 14 . \quad$ Disponible en: https://www.usal.edu.ar/archivos/geousal/docs/crecimiento_urbano_rio_gallegos_188 5- 2010.pdf 
CÁCERES, A. P., NORAMBUENA, M. V., AMPUERO, C., TRIVIÑO, G. (2013). "Consolidación de la Tercera Franja Residencial de Río Gallegos, Patagonia Argentina". Contribuciones Científicas Vol. 25, Sociedad Argentina de Estudios Geográficos GÆA. Buenos Aires.

CÁCERES, A. P., SEGOVIA, M., SOTO, J., NORABUENA, M., FRIAS, P., AMPUERO, C. (2016). "Posición geográfica de Río Gallegos en la Patagonia Austral". Actas científicas del Congreso Internacional de Geografía - $77^{\circ}$ Semana de la Geografía. GÆA, Sociedad Argentina de Estudios Geográficos. Buenos Aires.

CÁCERES, A., AMPUERO, C. (2008). "Análisis de la distribución espacial de Nodos de Servicios en la Segunda Franja Residencial de una ciudad intermedia patagónica como aporte al diagnóstico territorial’”. Boletín geográfico. Año XXX, N³1. Edición especial: VII Jornadas Patagónicas de Geografía. Departamento Geografía, Universidad Nacional del Comahue. Neuquén.

CARUT, C. B. (2012). "La delimitación del rururbano, análisis de los ámbitos territoriales en el Partido del Monte, Provincia de Buenos Aires (Argentina)". XI INTI International Conference La Plata, 17 al 20 de Octubre 2012. La Plata.

EXPEDIENTE $\mathrm{N}^{\circ}$ 13.520-1960. Acumulado $\mathrm{N}^{\circ}$ 15.233-1961. Río Gallegos. 9 de Julio de 1962.

GONZÁLEZ, C., CÁCERES, A. P. (2018). “Determinación del área de influencia del Nodo de Servicio (NS) de la Circunscripción III, Tercera Franja Residencial (TFR) de Río Gallegos". Informe final de beca de investigación. ICT-UNPA. Río Gallegos.

GONZÁleZ, C., CÁCERES, A. P., AMPUERO. C. (2019). "Delimitación Espacial de Unidades Territoriales Residenciales en la Circunscripción IV - Sección C, Río Gallegos". Informe final de beca de investigación. ICT-UNPA. Río Gallegos. Disponible en: https://doi.org/10.22305/ict-unpa.v11.n3.798

LAURELLI, E. (2004). "Nuevas Territorialidades: Desafíos para América Latina frente al siglo XXI”. Ediciones Al Margen. La Plata.

MUNICIPALIDAD DE RÍO GALLEGOS (2013). Ordenanza $\mathrm{N}^{\circ} 3259 / 98$ y modificatorias 3864/00; 3964/00; 4003/00; 4538/02; 4566/02; 4731/02; 4997/03; 5160/03; 5182/03; 5188/03; 6191/07; 6406/07; 6536/08; 6576/08; 6597/08; 6705/09. Río Gallegos.

MIRELMAN, S., LOLICH, S., FERNANDEZ MALLO, J. (2006). “Arquitectura pionera de la Patagonia Sur. Capítulos de la historia de Río Gallegos (1885-1940)”. Instituto Salesiano de Estudios Superiores.

PÉREZ, E. (2000). "Paisaje Urbano en nuestras ciudades". Revista Bitácora Urbano Territorial, primer semestre, número 004. Universidad Nacional de Colombia. Bogotá.

PERTILE, V. C. (2007). "Aportes conceptuales a la Geografía Urbana. La ciudad como fenómeno espacial. Aproximaciones al tema”. En: Revista Geográfica Digital. Instituto de Geografía, Facultad de Humanidades. Universidad Nacional del Nordeste. ISSN 1668-5180. No 8. Julio - Diciembre 2007.

PORTAL OFICIAL DEL INSTITUTO NACIONAL DE ESTADÍSTICA Y CENSO DE LA REPÚBLICA ARGENTINA (2018). Censo de 2010. Disponible en: https://www.indec.gob.ar/

REAL ACADEMIA ESPAÑOLA, RAE (2018). Diccionario enciclopédico de la lengua española. Disponible en: http://www.rae.es/

SÁNCHEZ HERNÁNDEZ, J. L. (2016). "Análisis de planos urbanos con Google Earth. Taller de Planos Urbanos". Universidad de Salamanca, Facultad de Geografía e Historia, Departamento de Geografía. Salamanca.

SANTOS, M. (2000). "La naturaleza del espacio. Técnica y tiempo. Razón y Emoción”. Ariel, $2^{\circ}$ ed. Barcelona. 
SALDIVIA, M., AMPUERO, C., CÁCERES, A. P. (2019). "Proceso de ocupación del suelo con el uso residencial en la Circunscripción IV - Sección B, Río Gallegos, Patagonia Austral Argentina". Revista Geográfica Digital, Vol. 16, № 31, 16-28 pp., DOI: https://dx.doi.org/10.30972/geo.16313612

SGROI, A. M. (2016). "Morfología Urbana - Paisaje Urbano”. Taller vertical Yantorno, ficha $\mathrm{N}^{\mathrm{o}}$ 19. Teorías Territoriales y Planificación Territorial I y II. Universidad Nacional de La Plata, Facultad de Arquitectura y Urbanismo. Buenos Aires.

SORRE, M. (1952). "Les fondements de la Géographie humaine”, Vol. III, L'Habitat, París, A. Colin, pág. 180.

VILAGRASA, J. (1991). "El estudio de la morfología urbana: una aproximación”. GeoCrítica, Cuadernos críticos de Geografía Humana. Universidad de Barcelona.

VILLALVAZO PEÑA, P., CORONA MEDINA, J. P. y GARCÍA MORA, S. (2002). "Urbano-rural, constante búsqueda de fronteras conceptuales". Revista de información y análisis núm. 20, 2002. México.

ZÁRATE, A. (1984). "El mosaico urbano. Organización interna y vida en las ciudades". Editorial Cincel. Madrid.

ZÁRATE MARTÍN, A. (1991). "El espacio interior de las ciudades”. Editorial Síntesis. Madrid.

ZOIDO NARANJO, F., DE LA VEGA BENAYAS, S., MORALES MATOS, G., MAS HERNANDEZ, R., LOIS GONZÁLEZ, R. (2000). "Diccionario de Geografía Urbana, Urbanismo y Ordenación del Territorio”. Capítulos 17, 18 y 20. Grupo ADUAR. Edición Ilustrada. Madrid. 